ARCHIVO ESPAÑOL DE ARTE, LXXXIX, 354

ABRIL-JUNIO 2016, pp. 183-193

ISSN: 0004-0428, eISSN: 1988-8511

doi: $10.3989 /$ aearte.2016.12

\title{
VARIA
}

\section{OBRAS INÉDITAS DE BERNARDO LORENTE GERMÁN}

\author{
Jesús Porres Benavides \\ Universidad Rey Juan Carlos \\ jesus.Porres@urjc.es
}

En el presente artículo damos a conocer varias obras inéditas que atribuimos o certificamos del pintor sevillano Bernardo Lorente: Santas Justa y Rufina, la Virgen con el Niño, San Bernardo, San Cristóbal y La Anunciación. Palabras clave: Bernardo Lorente Germán; Pintura barroca sevillana; Iconografía.

\section{UNPUBLISHED PAINTINGS BY BERNARDO LORENTE GERMÁN}

In this article the author presents and attributes several unpublished paintings to the Sevillian artist Bernardo Lorente (1680-1759): Saints Justa and Rufina, The Virgin with the child Jesus, Saint Bernard and The Annunciation.

Key words: Bernardo Lorente Germán; Sevillian baroque painting; Christian iconography.

En los últimos años ha crecido el interés por la figura del pintor sevillano Bernardo Lorente Germán (1680-1759) sobre todo a partir de la publicación del libro de Fernando Quiles e Ignacio Cano que lleva por título Bernardo Lorente Germán y la pintura sevillana de su tiempo (1680$1759)^{1}$. No obstante, el corpus pictórico del artista se ha visto enriquecido últimamente con la incorporación de obras procedentes del mercado del arte y de distintas colecciones particulares ${ }^{2}$.

\footnotetext{
${ }^{1}$ Quiles García/Cano Rivero, 2006. También han salido otros artículos como Ruiz Barrera, 1999:227-234.

2 Entre los ejemplos citamos una Divina Pastora vendida en la Galerie Koller de Zurich en el año 2013 y una Santa Rosa de Lima en Subastas Segre en 2012, firmada y fechado en 1732, un San Miguel luchando contra el demonio de Alcalá Subastas (Madrid) se vendía en febrero de 2013. Es un óleo sobre lienzo de 64,6 x $51 \mathrm{~cm}$. parecido a otro que se subastó en Subastas Segre (Madrid) en junio de 2009 o el de la galería de José de la Mano (Madrid) fechado ilegible 173xxx., procedente de una colección particular de Mallorca $(46$ x $40 \mathrm{~cm})$. También recordar el gran arcángel San Miguel que vendía la galería Coll y Cortes. De la misma galería la pareja de cuadros Trampantojo con figuras escultóricas, grabados y una cortina y Trampantojo con partituras, un boceto, libros, cartas y un pequeño cuadro sobre una repisa de madera. El segundo firmado: Bernardo Luis Lorente fact. En 2015 salió un interesante cuadro de San Esteban Protomartir en Segre Subastas catalogado como "Escuela Toledana S. XVII" con medidas: 85 x $73 \mathrm{~cm}$. Discrepamos de la catalogación pues es un cuadro indiscutible del autor, actualmente en la colección Sánchez Lópiz de Madrid.
} 
Lorente representa el culmen de modernidad de la primera generación de pintores del siglo ${ }^{3}$ XVIII en Sevilla junto a Domingo Martínez y, quizás, Tovar. La formación inicial de Lorente Germán tiene lugar en el taller paterno, que pronto abandona para ingresar en el obrador de Cristóbal López (1671-1730) ${ }^{4}$, pintor de mediocre talento, cuyas obras siguen fielmente el arte de Murillo. En este sentido viene bien recordar las palabras del conde del Águila quien afirmó que Lorente "diose como todos los de su tiempo a copiar e imitar a Murillo, no pudo sustraerse en la copia de Murillo, como sus contemporáneos, pero al mismo tiempo, siguió otros derroteros creativos" Afirmación que se puede corroborar en algunas de sus obras como el cuadro de La anunciación que ahora presentamos. No cabe duda que en ambos talleres adquirió una sólida base técnica, así como aparejos compositivos derivados del mundo del grabado, del que llegó a poseer una excelente colección ${ }^{6}$. En algunos documentos de inicios del XVIII figura como "pintor de imaginería", aunque en un contrato cercano a 1720 se le cita como maestro del ynsigne arte de la pintura $^{7}$. Hasta 1726 no comienza a fechar su producción pictórica por lo que resulta harto complicado esclarecer la cronología de sus primeras obras.

Lorente Germán encontró su clientela entre el público devoto, en su mayoría religiosos ${ }^{8}$, hermandades $^{9}$ y particulares ${ }^{10}$, que le requerían pinturas devocionales como las Divinas Pastoras ${ }^{11}$, aunque su producción pictórica abarca otros géneros como el retrato ${ }^{12}$ (entre los que llegara a retratar al propio infante don Felipe de Borbón), escenas de género como representaciones mitológicas o trampantojos e incluso Vanitas.

Parece que tuvo la oportunidad de trabajar junto a los pintores que se ganaron el favor del rey Felipe V durante la estancia de la Corte en Sevilla, en tiempos del Lustro Real, y que incluso disputó con el famoso pintor de cámara Jean Ranc la ejecución de un retrato real. En sus últimos años fue distinguido como académico de mérito de la Real Academia de San Fernando "en atención a la fama notoria de pericia y singular habilidad del pretendiente"13. Hacia mediados de siglo se conoce su labor como tasador entre la distinguida clientela sevillana, civil y religiosa ${ }^{14}$.

\footnotetext{
${ }^{3}$ Quiles García, 1995: 31.

${ }^{4}$ Sobre este artista véase Clavijo García, 1979: 25-46.

${ }^{5}$ Valdivieso, 2003: 504. Aunque sí es verdad que Lorente no copia literalmente composiciones de Murillo tan frecuentemente como lo hicieran otros pintores, es un pintor que estilísticamente está conectado con aquel y que incluso llegó a tasar algún cuadro de él. Además, sabemos que en la buena colección de pintura que debió tener, había algún cuadro que se atribuía a Murillo en Mata Torres, 1986:215-222.

${ }^{6}$ Valdivieso, 2003: pp. 31-43. Se sabe que poseía más de seiscientas estampas, que van de Goltzius a grabadores franceses.

${ }^{7}$ Quiles García/Cano Rivero, 2006:204

${ }^{8}$ Entre los que sabemos que trabajó para la cartuja de Jerez. ver Aranda Bernal, 1989: 125-126.

${ }^{9}$ Cano Rivero le atribuye el ovalo de la Virgen del Rosario propiedad de la hermandad de Santa Marta de Sevilla, que presentamos aquí de manera inédita. Este formaría parte de un estandarte procesional de la sacramental de San Andrés de Sevilla. La virgen sedente es un trasunto pictórico de la imagen que preside la capilla sacramental obra de Valdés Leal como ya diera a conocer José Roda. Esta en un rompimiento de gloria con ángeles alrededor y un bello celaje ocre dorado. Tiene unas medidas de $47 \mathrm{~cm}$. x $34 \mathrm{~cm}$.

${ }^{10}$ Ceán recuerda que hay muchas en las casas de los particulares de Sevilla, y muchas más salieron fuera del Reyno, reputadas por de mano de Murillo en Ceán Bermúdez, 1800:182.

${ }^{11}$ Esta iconografía de la Divina Pastora fue propulsada por fray Diego de Cádiz y algunos pintores como Tovar desarrollaron esta temática.El propio Ceán Bermúdez le citará en su famoso Diccionario como "el pintor de las pastoras", indicación que ha servido de socorrido tópico para atribuirle después todo tipo de representaciones pastoreñas. Valdivieso, 2003:504.

${ }^{12}$ Ver por ejemplo Gutiérrez Pastor, 1999: 174-181.

${ }_{13}$ Quiles García/Cano Rivero, 2006: 222.

${ }^{14}$ Es interesante por ejemplo un informe en que el autor declara: "que abiendo sido llamado por parte de los Sres hermanos mayores y alcaldes de la ermandad del Smo sacramento de la iglesia parroquial de santa maria la blanca
} 
$\mathrm{Su}$ obra se concentra sobre todo en Sevilla, aunque en los últimos años han salido a la luz varias pinturas suyas en otros puntos de la geografía española, lo que nos lleva a pensar que su fama debió de transcender el ámbito sevillano. Algunos estudiosos del pintor como Pedro Galera ${ }^{15}$, han analizado algunas de estas obras que se encuentran desde antiguo en la provincia de Jaén en iglesias y en colecciones particulares. Así como las pinturas de San Andrés y Santa Catalina de Siena del retablo de la antigua capilla de Nuestra Señora de la Concepción de la catedral cordobesa firmados por él ${ }^{16}$.

La primera de las obras que incluimos en su producción (fig. 1), una pintura al óleo sobre lienzo de lino tipo tafetán, la hemos localizado en una colección particular sevillana y representa a las jóvenes mártires y patronas de Sevilla, Santa Justa y Rufina ${ }^{17}$. De Lorente conocemos dos versiones de santa Justa realizadas anteriormente ${ }^{18}$. En ambas versiones está representada sola ${ }^{19} \mathrm{y}$ aparece sobre uno de los fondos oscuros que tanto gustaban al pintor.

La iconografía de estas santas parece que la define el pintor Miguel de Esquivel, y aunque hay otros ejemplos algo anteriores, sería Murillo el que crea el referente pictórico, en el cual se basan las demás representaciones posteriores ${ }^{20}$, incluida la que ahora comentamos.

En el cuadro de Lorente, las santas aparecen de pie, vestidas elegantemente con las túnicas de tipo romano y sus correspondientes mantos, incluso una de ellas parece que en las mangas de la camisa (que parece una malla o cota) tiene las típicas lengüetas de época romana. Quizás influenciado por Domingo Martínez, las santas lucen unos coquetos lazos en el cabello. Portan la Giralda entre sus manos y a sus pies tienen los cacharros de loza tan típicos de su labor de alfareras y que son parte de sus atributos. También portan unas palmas, símbolo de su martirio. Se encuentran en un paisaje campestre con un gran fondo de celaje claro con el que contrastan las figuras de ambas.

En la obra se aprecia la gran calidad técnica del autor sobre todo en cuanto al tratamiento de las carnaciones y en los detalles tan realistas como el pequeño bodegón de piezas de loza que se encuentra a sus pies.

El siguiente cuadro que le atribuimos representa de La genealogía de la Virgen o La Sagrada Parentela $^{21}$. Con el mismo tema, aunque con una composición más simplificada, conocemos otra obra del autor de 1748, dada a conocer por Angulo, en el que aparece la Virgen con el niño Jesús en su regazo mostrándolo al espectador, con sus padres y San José.

para ver y recnoser y apreciar un quadro propio de dicha hermandad pintura del misterio de la sena, original de Don Bartolome Murillo" en dicho informe hace consideraciones interesantes sobre el estado de la obra como "el perjuicio de lo ahumado de las luces del tiempo que estuvo colocado en el altar" tasándolo al final "según lo que yo alcanso en el arte dem protección” "en "vn mil pesos de asiento y veinte y ocho quartos" Aprecio de Bernardo Lorente Germán referente a «La Cena". Núm. Registro 2-1215.Fototeca del Laboratorio de Arte. Universidad de Sevilla.

${ }^{15}$ Galera Andreu, 1988: 207-211. Habría que tomar en consideración la cita de Ceán Bermúdez que dice "era insigne pintor y entre los muchos monumentos que a dexado en pintura seria son los de la cartuxa de Xeres de la Fra, los de la Iglesia de Baeza y parece que en Ubeda".Parece ser que su familia era de oriunda de Baeza, pues en 1740 otorga poderes a Alonso Bacuende para que investigara en los archivos parroquiales del lugar de Seron en Baeza "a fin de prouar y aueriguar mi descendencia".

${ }^{16}$ Las pinturas de tamaño mediano se insertan en un retablo renacentista y son de gran calidad. Nieto Cumplido, $2007: 404$

${ }^{17}$ El cuadro se encuentra firmado con la siguiente inscripción "Bern. Due Lorente german faciebat. Año 1753 ”" y mide $90 \times 106 \mathrm{~cm}$.

${ }^{18}$ Una en la colección Martín Laguillo de Sevilla y otra en paradero desconocido, anteriormente en Inglaterra publicado por Quiles García/Cano Rivero, 2006.

${ }^{19}$ Decimos que es Santa Justa, y no Santa Rufina por su catalogación por autores anteriores, aunque sin duda, es complejo distinguirlas iconográficamente.

${ }^{20}$ Incluso las escultóricas, como la pareja que proveniente del Salvador está hoy en la catedral, de Duque Cornejo.

${ }^{21}$ Agradecemos a Ignacio Cano Rivero la consulta de esta imagen.

Arch. esp. arte, LXXXIX, 354, ABRIL-JUNIO 2016, 183-193

ISSN: 0004-0428, eISSN: 1988-8511, doi: 10.3989/aearte.2016.12 


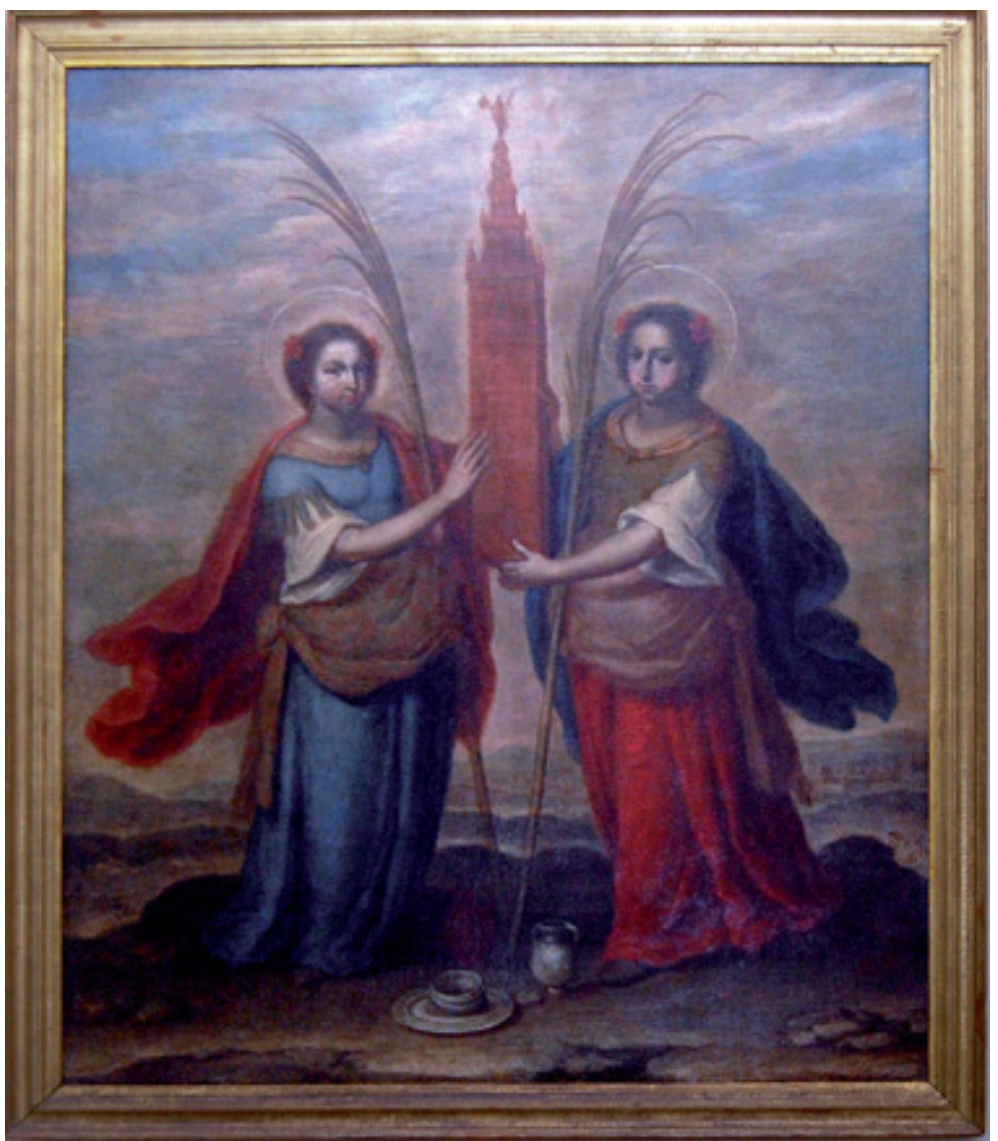

Fig. 1. Santa Justa y Rufina. Firmado y fechado: Bernardo Lorente Germán, 1753. Colección particular de Sevilla.

El cuadro (fig. 2) se encuentra en la iglesia de San Sebastián de Sevilla, actualmente en el muro del lado de la epístola. La obra tiene dos planos, en medio de los cuales está la Virgen María sedente, con su divino hijo en brazos, que sostienen el rosario con el que parece jugar. El plano superior o celestial está presidido por Dios Padre con los brazos extendidos, con los que pretende acoger a la pareja, de este se despliega la paloma del Espíritu Santo (con lo que unido a la figura de Jesús infante representa la Trinidad completa). Los ángeles que se encuentran a los lados de Dios Padre, portan atributos marianos como un pocito o una torre -haciendo referencia a la letanía lauretana- o simplemente revolotean alrededor. En el plano de abajo, se encuentra la familia o la "estirpe" de María y Jesús, a ambos lados de estos y se disponen algo escalonados. En el lado derecho estarían agrupado san Juan Bautista niño (con su correspondiente cartela del Agnus Dei) con sus padres Isabel y Zacarías y en el izquierdo estarían el esposo de María, José, que porta su atributo más característico, la vara florecida y los padres de la Virgen, Joaquín y Ana. La imagen de la Virgen esta soportada por una nube de ángeles entre querubines y angelillos que portan otros símbolos de la madre de Dios como la estrella (Stella matutina) o la rosa (rosa mystica). La obra ${ }^{22}$ se encuentra ampliada de su formato original y quizás hubiera formado parte un encuadre arquitectónico ${ }^{23}$. Aunque se encuentra en regular estado de conservación, con numerosos repintes (al-

\footnotetext{
${ }^{22}$ Mide 2'50 x 1'15 m en su formato actual y se trata al menos de dos piezas de tela de lino unidas.

${ }^{23}$ Pues no parece un formato cuadrangular sino polilobulado-cuadrangular.
} 


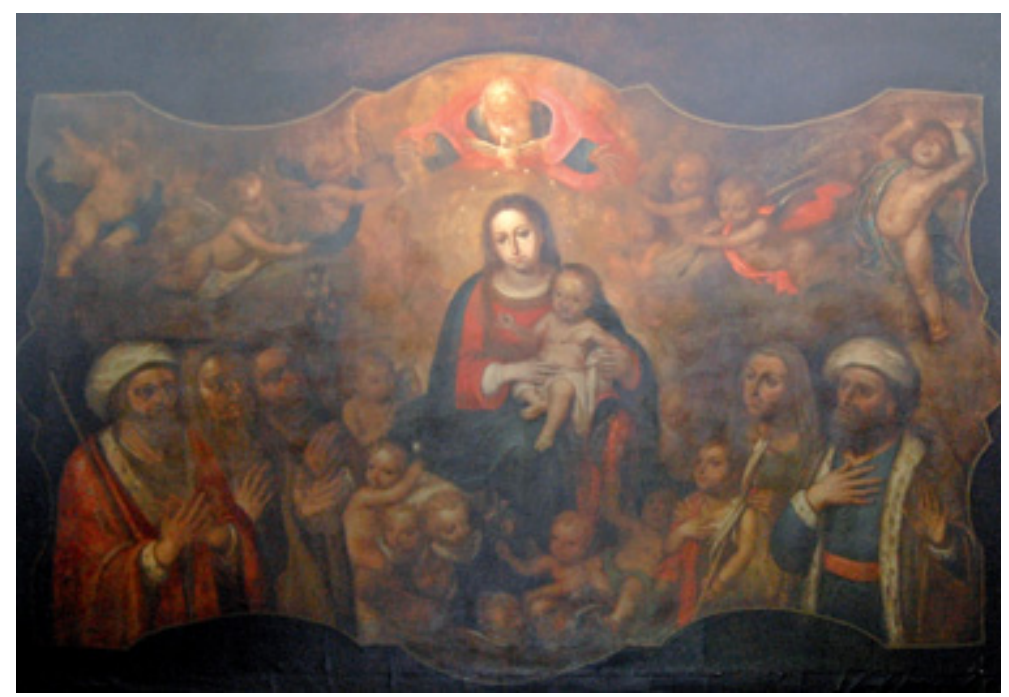

Fig. 2. Sagrada parentela o Genealogía de la Virgen. Atribuido a Bernardo Lorente. Segundo tercio siglo XVIII. Iglesia de San Sebastián. Sevilla.

gunos incluso en rostros de los personajes) que alteran su calidad inicial si podemos ver las características generales del periodo de madurez del pintor como es esa atmosfera de tonalidad parduzca $^{24}$ de donde emergen sabiamente vestimentas y carnaciones con hábiles toques de luz y color. Algunos personajes femeninos (Virgen o santa Isabel) tienen el rostro prototípico del pintor con narices finas y alargadas y ojos redondeados con grandes pupilas negras.

Otra obra atribuida es el San Bernardo de Claraval $^{25}$ (fig. 3), aparecida recientemente en una subasta de arte. Se trata de un lienzo ovalado, donde aparece la figura del santo en tres cuartos con atributos pasionistas como son la cruz, una caña con hisopo, una fusta y una corona entre sus manos, que es lo que se suele denominar como Arma Christi y que es frecuente que acompañe a san Bernardo en algunas representaciones, como los grabados de Hieronimus Wierix de 1619 o el de Cornelis Cort de $1576^{26}$. Se encuentra mirando hacia arriba como dirigiéndose a la divinidad. El rostro y en particular el tratamiento que hace de los ojos recuerdan a otras obras de Lorente. Esta obra tiene parecido con el San Millán de la Cogolla realizado en 1747 para la catedral de Sevilla. También por comparación de los tipos fisonómicos (humanos y el caballo en que monta el santo) se puede relacionar el espectacular san Millán para la colegial del Salvador de Sevilla, una obra de grandes dimensiones. ${ }^{27}$

Otra pintura inédita que atribuimos a Lorente es un San Cristóbal (fig. 4), de tamaño muy grande como suele corresponder a las obras de esta iconografía ${ }^{28}$, en la iglesia matriz de San Juan Bautista de Marchena. Esta obra datada como obra anónima del siglo XVIII fue intervenida en los años 60 por los servicios centrales de Restauración del Patrimonio ${ }^{29}$. Iconográficamente tiene

${ }^{24}$ Aquí debida sin duda a la imprimación ocre-parda típica preparación sevillana y que deja al descubierto en grandes zonas.

${ }^{25}$ Agradecemos a José Luis Requena la identificación iconográfica de esta obra y a la lectura y revisión del artículo. La pintura se vendió en Ansorena en mayo de 2012.

${ }^{26}$ Consultado on line en la Web de la National Gallery of London.

${ }^{27}$ Una obra que se relacionaba con Sebastián de Llanos Valdés y con medidas de 291 h. x 196 a. cm.

${ }^{28}$ Quizás por derivación del San Cristóbal realizado por Mateo Pérez de Alesio en la catedral sevillana, que al lado de la puerta podía tener el sentido de saludar o despedir al caminante o viajero.

${ }^{29}$ Agradecer a Juan Luis Ravé Prieto dicha información.

Arch. esp. arte, LXXXIX, 354, ABRIL-JUNIO 2016, 183-193

ISSN: 0004-0428, eISSN: 1988-8511, doi: 10.3989/aearte.2016.12 


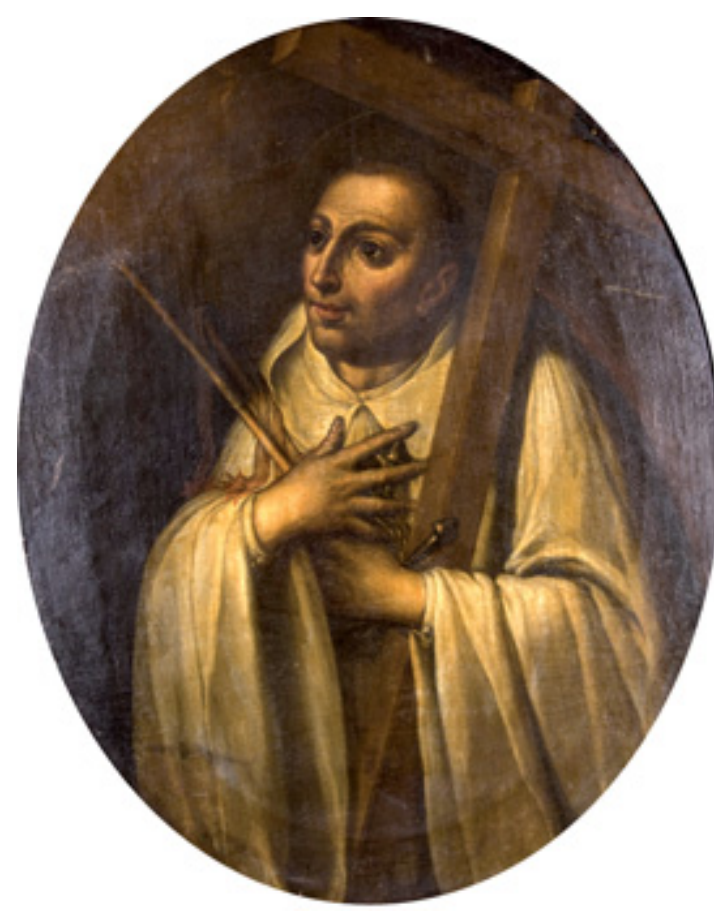

Fig. 3. San Bernardo de Claraval. Atribuido a Bernardo Lorente. Segundo tercio siglo XVIII.

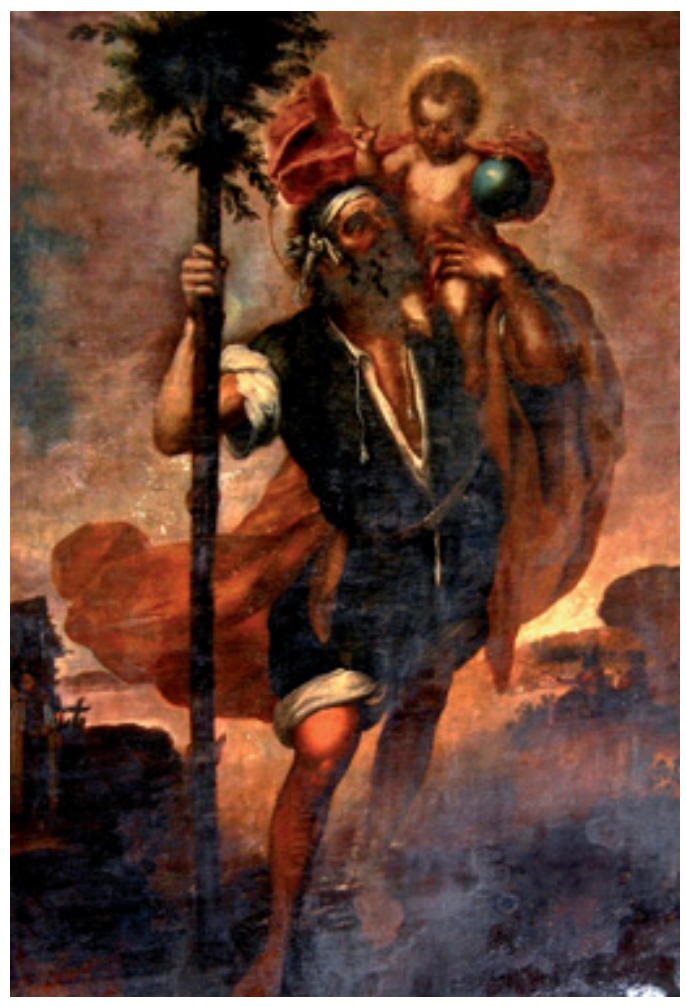

Fig. 4. San Cristóbal.Atribuido a Bernardo Lorente. Segundo tercio siglo XVIII. Iglesia matriz de San Juan Bautista de Marchena (Sevilla).

(C) Manuel Benítez Borrego.

cierto parecido a la de Mateo Pérez de Alessio de la catedral sevillana, sobretodo en la composición del paisaje con el ermitaño, el río que atraviesa el santo y las orillas. De Lorente conocíamos otra versión en la fundación Comes de $\mathrm{Cádiz}^{30}$ que sigue más fielmente el modelo de Alessio aunque con el estilo de él ${ }^{31}$. El santo representado como un gigante ${ }^{32}$, porta en sus hombros al niño Jesús que le bendice bajo su atenta mirada. Va vestido sencillamente con la camisa abierta y arremangada al igual que los pantalones, porta en su mano derecha un árbol que le sirve como bastón o apoyo. La obra tiene las tonalidades propias de Lorente, luminosas a veces, pero con el uso de espalto ${ }^{33}$ en zonas de oscuridad. Es especialmente prototípico el niño Jesús, parecido a otros que aparecen en sus obras ${ }^{34}$ y el rostro del santo oscurecido por el efecto del sol en su misión diaria de transportar

${ }^{30}$ Con medidas $148 \mathrm{~cm} \times 123 \mathrm{~cm}$.

${ }^{31}$ Observable en sus rostros y la técnica más desenvuelta de Lorente.

${ }^{32}$ La tradición lo describe como un gigante cananeo, que tras su conversión al cristianismo ayudaba a los viajeros a atravesar un peligroso vado llevándolos sobre sus hombros.

${ }^{33}$ Conocida es la mención de Ceán "dio en la manía de ennegrecer sus obras con espalto para darle más fuerza de claro-oscuro, pero el tiempo las puso en tal tono de confusión que en algunas apenas se conoce el asunto que representan" que sin duda dice mucho de su peculiar manera, donde resalta los contrastes cromáticos poniendo destellos de luz que brillan encima de zonas umbrías.

${ }^{34}$ Como el que comentamos a continuación de la Virgen con el Niño y San Juan. 
caminantes. Es interesante como el artista diferencia con esa tonalidad clara o nacarada a imágenes sacras como la Virgen, el niño Jesús o a los ángeles. La atribución a Lorente además está reforzada por la comparación con el otro san Cristóbal, obra segura suya.

Otra obra que atribuimos a Lorente es una Virgen con el Niño y San Juanito ${ }^{35}$ (fig. 5). La Virgen sedente sostiene a Jesús infante sobre sus rodillas que mira al espectador en actitud de bendecir con la mano izquierda alzada. La composición recuerda vagamente a otras de $\mathrm{Mu}$ rillo como la Virgen con el Niño, pintado entre los años 1660 y 1665 , perteneciente a la Colección Masaveu ${ }^{36}$, en cuanto al encuadre, la gama cromática y sobre todo la forma como coge María a su hijo en una actitud maternal, pero sin la maestría de aquel. La mano derecha del Niño descansa sobre la mano de la Virgen que también mira al espectador.

El rostro de la Virgen se corresponde con el modelo femenino que Lorente recrea en algunos personajes (no sabemos si corresponde a un modelo real o inventado) como el rostro de la santa Justa (de la derecha del cuadro) o la Virgen de la Genealogía de María comentados anteriormente. En el ángulo inferior está la figura de San Juanito (en tonos marrones en llamativo contraste cromático con las otras figuras que son de una piel

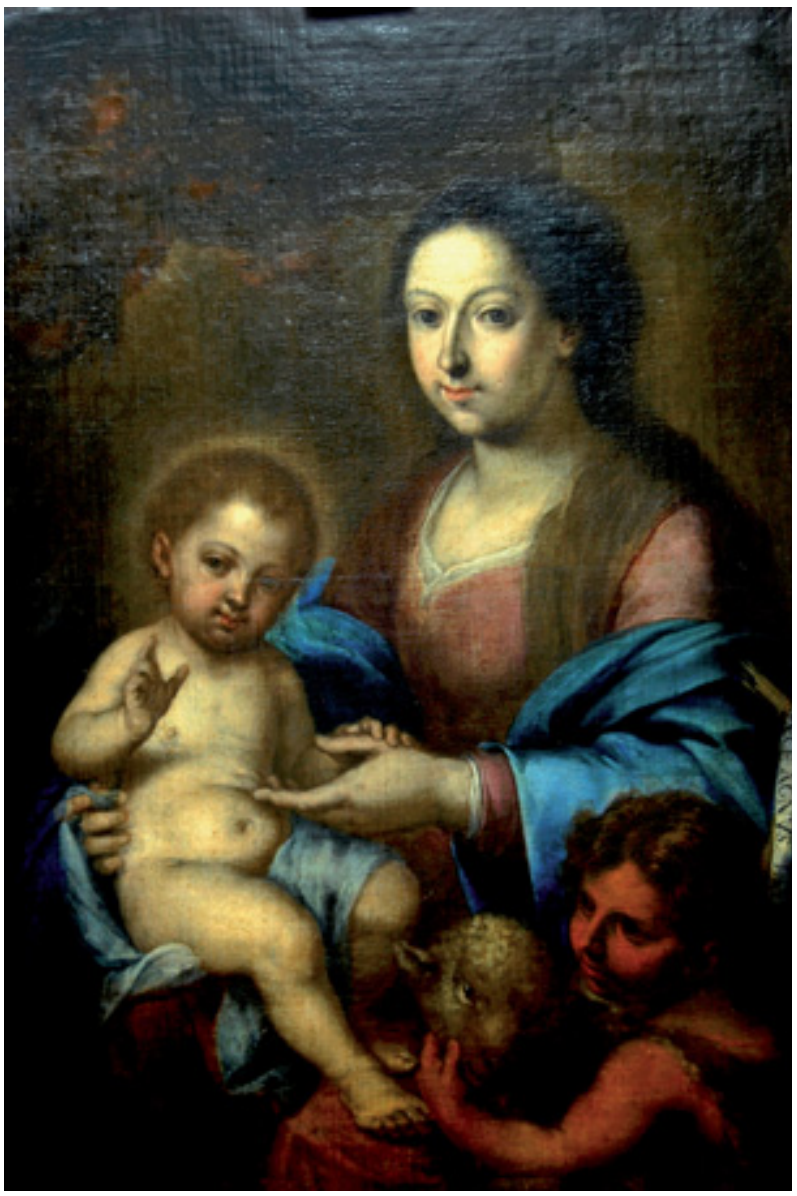

Fig. 5. Virgen con el niño y san Juanito. Atribuido a Bernardo Lorente. Segundo tercio siglo XVIII. Colección particular Sevilla. clara) que parece jugar con un cordero portando su típica banderola con la leyenda (Ecce Agnus Dei). En el ángulo superior izquierdo aparecen un grupo de ángeles que contempla la escena ${ }^{37}$.

Esta pintura se ha realizado sobre un soporte de lino fino tipo tafetán ${ }^{38}$. Su estilo pictórico está influenciado por la pintura francesa, casi rococó, a partir del $2^{\circ}$ tercio del XVIII tras haber conocido a pintores como Jean Ranc. Parte de una imprimación parda, quizás a base de tierras, desde donde construye las figuras. Hay detalles de sabia abstracción, que al alejarnos nos dan esa

${ }^{35}$ La obra, un lienzo de lino, mide $109 \mathrm{~cm}$ x $81 \mathrm{~cm}$.

${ }^{36}$ Cano Rivero le atribuye la copia de esta pintura que se encuentra en la Real Academia de San Fernando de Madrid con el núm. 1185 y titulada como "Copia de Murillo". Esta atribución podría ser cierta, si además sabemos que Lorente fue académico y por lo tanto regalara esta obra a la Institución.

${ }^{37}$ En el inventario que se le hizo tras su muerte, aparecía una virgen del Rosario con San Juan que podría ser semejante a esta en Quiles García, 1995:38.

${ }^{38}$ Como es propio de las pinturas del XVIII.

Arch. esp. arte, LXXXIX, 354, ABRIL-JUNIO 2016, 183-193

ISSN: 0004-0428, eISSN: 1988-8511, doi: 10.3989/aearte.2016.12 


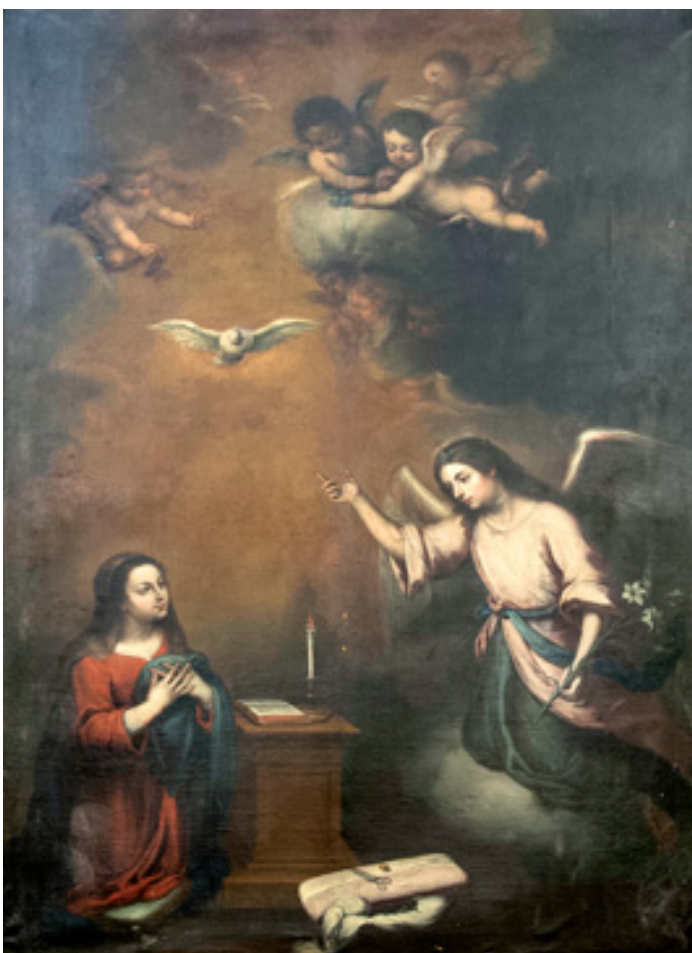

Fig. 6. La anunciación. Firmada y fechada por Bernardo Lorente en 1741. Capilla universitaria en la antigua fábrica de Tabacos, actual rectorado de la Universidad de Sevilla. (C) Manuel J. Esteo.

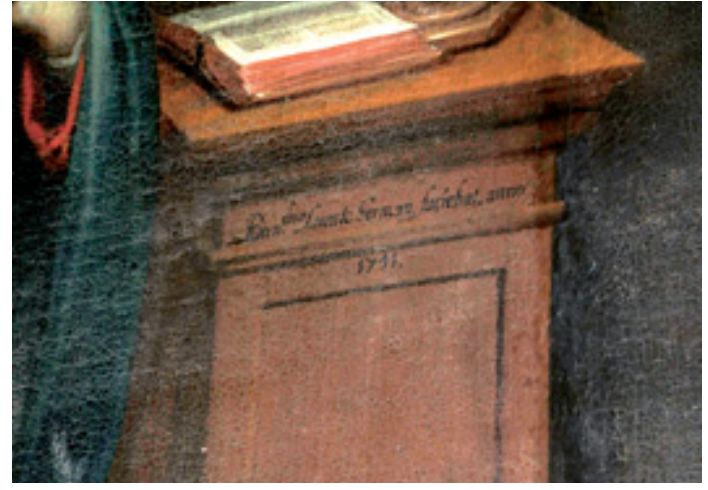

Fig. 7. Firma y fecha en el cuadro de La anunciación. Capilla universitaria en la antigua fábrica de Tabacos, actual rectorado de la Universidad de Sevilla. (C) Manuel J. Esteo.

sensación de realidad, perceptible en zonas como el tratamiento del pelo del corderito o algunas áreas del cuerpo del Niño, así como los dedos de la Virgen. El tratamiento de emplastes para sacar zonas de luz es muy interesante en algunos puntos, como el manto en el brazo derecho o el modo en que modela la anatomía del pecho y abdomen del Niño partiendo de esa imprimación parduzca o esos puntos de blanco de albayalde en zonas como los reflejos de las pupilas o la punta de las narices. También están muy bien resueltos los trazos en tierra mezclada con negro de carbón en zonas como las comisuras de los labios o el trazo de la línea de los brazos del niño que nos proporcionan una sensación de vibración. Adicionalmente, ha utilizado lacas orgánicas amarillas que presentan un alto grado de decoloración.

Por último tenemos que añadir la pintura de La Anunciación (fig. 6) de la capilla universitaria en la antigua fábrica de Tabacos, firmada y fechada Bern ${ }^{d u s}$ Lorente Germán faciebat anno $1741^{39}$ (fig. 7). El cuadro se basa en el realizado por Murillo del mismo tema (actualmente en el Museo de Bellas Artes de Sevilla, pero proveniente del convento de Capuchinos), del que copia literalmente la escena, cambiando algunos detalles como la eliminación de una nubecilla con cabezas de querubes encima de la Virgen o la postura de las manos de esta, que en vez de estar sobre la

${ }^{39}$ La obra esta inventariada con el número 0956-00-REC-PINT. N ${ }^{\circ}$ Inv. Sorolla 101968. Tiene unas medidas de 317 x $210 \mathrm{~cm}$ y está compuesto por dos grandes piezas de lino verticales unidas al centro y camuflada la costura por una intervención antigua de la cual queda el repinte.

Arch. esp. arte, LXXXIX, 354, ABRIL-JUNIO 2016, 183-193 ISSN: 0004-0428, eISSN: 1988-8511, doi: 10.3989/aearte.2016.12 


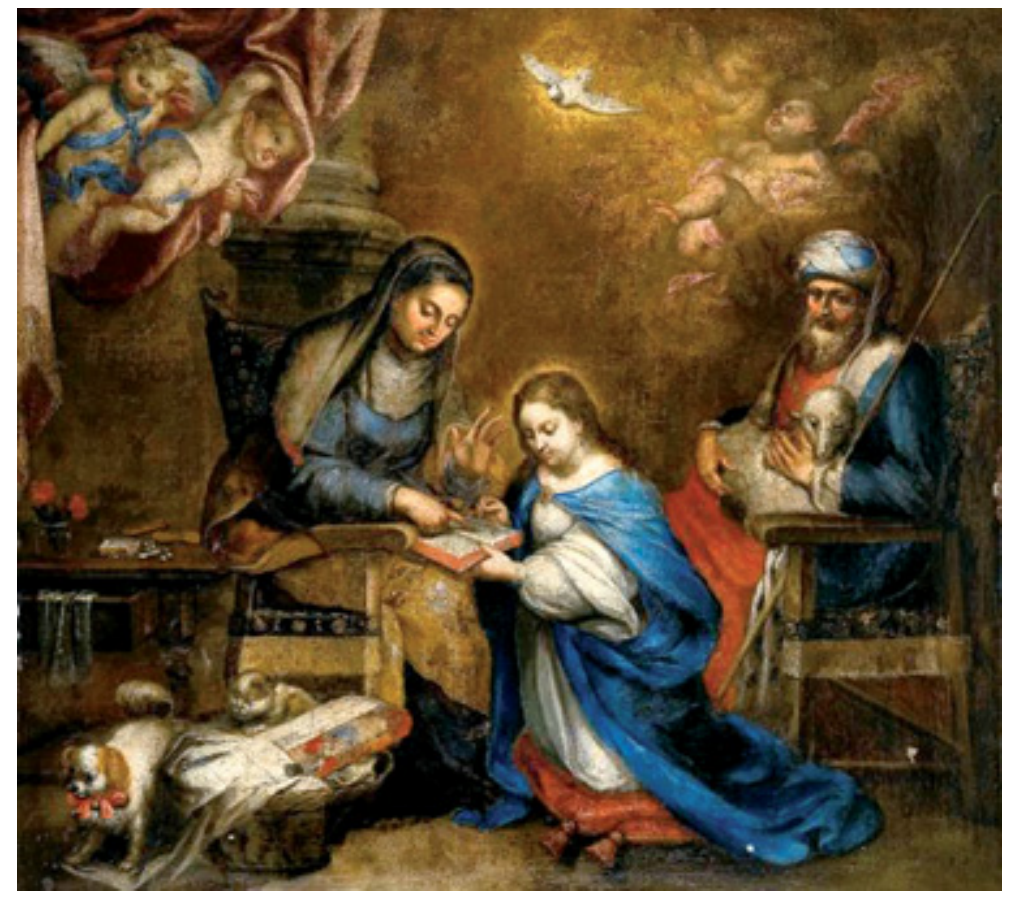

Fig. 8. La educación de la Virgen. Atribuido a Bernardo Lorente. Segundo tercio siglo XVIII.

mesa al lado del libro las tiene sobre el pecho. Adicionalmente introduce una palmatoria con una vela en dicha mesa y coloca su firma en la moldura superior de esta. Debemos resaltar que en este mismo año realiza otra pintura del mismo tema inspirada ${ }^{40}$ en una composición murillesca y en donde aparecen algunas zonas muy parecidas como la cesta de labor, la mesa donde están los libros y la vela, la atmosfera donde se representa la escena o la propia Virgen, aunque cambiada de postura. Esta pintura ha sido erróneamente atribuida a Diego Bejarano y fechada hacia 1763 en la ficha del catálogo. La obra hace pareja con otra de La adoración de los pastores (también una versión de Murillo) pero que no parece ser de Lorente.

Aun sin la certeza de las obras anteriores, finalmente debemos reseñar como cuadros dentro del estilo de Lorente los siguientes:

La educación de la Virgen (fig. 8) que salió recientemente a subasta ${ }^{41}$ atribuida al pintor Clemente de Torres (Cádiz, 1662-1732). La obra representa a santa Ana sedente que enseña a su hija los primeros rudimentos de lectura. Torres ${ }^{42}$ es un pintor del que apenas conocemos algunos datos biográficos: trabajó en la decoración de la iglesia de San Pablo de Sevilla, donde se le atribuyen con certeza algunos de los apóstoles de los pilares de la iglesia ${ }^{43}$ y algunos cuadros de pequeño tamaño. Por tanto, nos parece algo arriesgada esta atribución, primero por la poca obra segura de él y porque esta pintura no tiene demasiado que ver con lo conocido suyo. En cambio hay ciertos detalles que nos acercan a Lorente. Primero ese fondo oscuro terroso en el que sobresalen las tres

${ }^{40}$ Fue subastada en el 2002 en Arte Información y Gestión y tenía unas medidas de 195 x $250 \mathrm{~cm}$.

${ }^{41}$ En Segre Subastas. Subasta de Pintura. 17 de Diciembre 2013 con el lote ${ }^{\circ} 125$. Medidas 104 x $115 \mathrm{~cm}$.

${ }^{42}$ Clemente de Torres es el nombre artístico de Clemente de Torvisco y Escobar. (Cádiz, 23 de noviembre de 16621732) seguramente de origen genovés.

${ }^{43}$ Cuyo ímpetu de impostación y factura corrobora la tradición que le hace discípulo de Valdés Leal.

Arch. esp. arte, LXXXIX, 354, ABRIL-JUNIO 2016, 183-193

ISSN: 0004-0428, eISSN: 1988-8511, doi: 10.3989/aearte.2016.12 


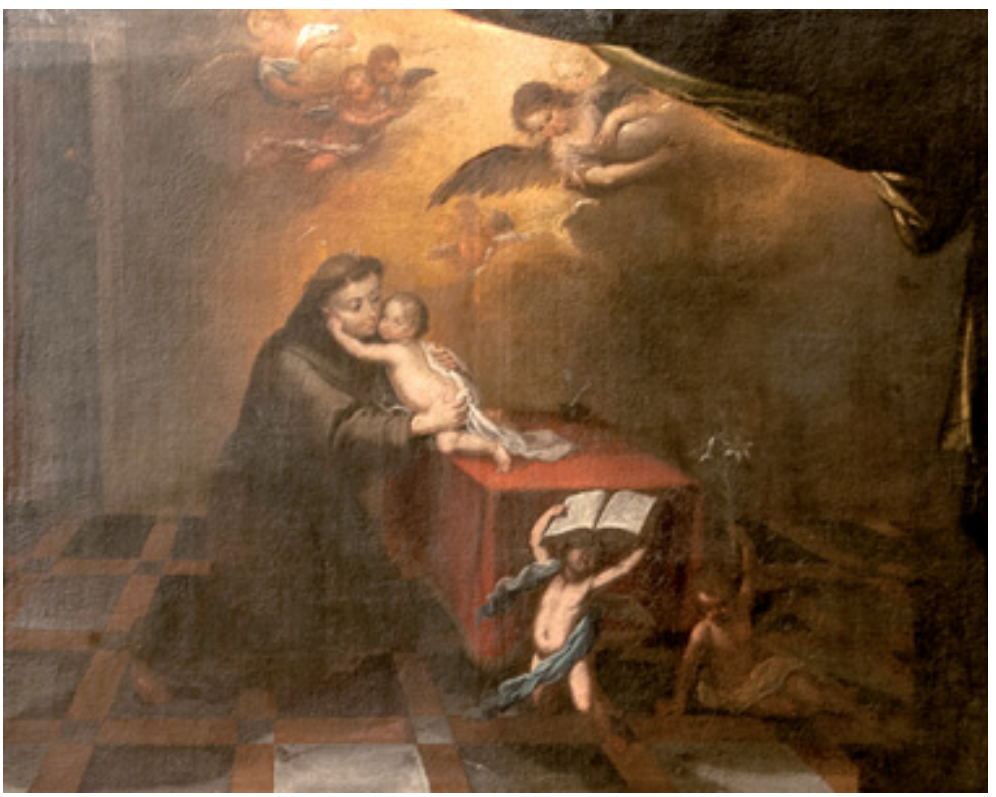

Fig. 9. Aparición del niño Jesús a San Antonio.

Atribuido a Bernardo

Lorente. Segundo tercio siglo XVIII. Colección particular Sevilla. (C) Manuel J. Esteo.

figuras, el tratamiento de los blancos y de la paleta cromática en general (donde destacan los azules, rojos y rosas),el rostro de algunos personajes como el San Joaquín que recuerda a otros personajes masculinos de Lorente o algunos angelillos, el tratamiento minucioso que da a algunos objetos como los muebles, las piezas que hay encima del bodegón, la cesta de labores y los propios animales, en especial el perro con ese lacito (que hemos visto en otras obras de Lorente). También está el hecho del tratamiento parecido que da Lorente en otros cuadros atribuidos con esta misma temática, como el conservado en los Capuchinos de Sevilla ${ }^{44}$. El tratamiento del san Joaquín sedente y atento a la escena se asimila bastante a esta, así como las imágenes de la santa y su hija aunque invertidas. Todo esto nos lleva a atribuir esta obra al círculo de Lorente.

Otra obra que considero cerca del estilo del autor y que está en la misma colección que la santas Justa y Rufina es La aparición del niño Jesús a San Antonio de Padua ${ }^{45}$ (fig. 9). En ella vemos la iconografía habitual en la que el santo se encuentra de rodillas en su celda y ante la sorpresa del hermano, que observa la escena escondido detrás de la puerta, el niño Jesús se le aparece bajado del celaje que se ha abierto ante la mirada de ángeles y querubines. El tratamiento de los ángeles parece estar sacado de alguno de los grabados que Lorente solía utilizar.

Estas obras inéditas que damos a conocer (Santas Justa y Rufina, La parentela de la Virgen, la Virgen con el Niño, San Bernardo, San Cristóbal y La Anunciación) vienen a engrosar el corpus pictórico del pintor Bernardo Lorente que aunque todavía exiguo, ha ido creciendo en los últimos años. Además nos proporciona una valiosa información sobre el método de trabajo del pintor, en el que alterna el uso de estampas ${ }^{46}$, con modelos copiados sobre todo de Murillo y su escuela, pero

${ }^{44}$ Aunque proveniente de una colección particular madrileña. Tiene unas dimensiones menores y se encuentra simplificado, también el tema tiene la variación de que Santa Ana enseña labores de costura a su hija.

${ }^{45}$ El cuadro tiene un formato apaisado y mide $89 \times 105 \mathrm{~cm}$.

46 Del que sabemos que tenia por ejemplo “doze cuadernillos de estampas y principios del arte”en Quiles García/Cano Rivero, 2006: 313. 
reelaborándolas de una manera muy inteligente y sutil. La mayoría de las pinturas son de mediano formato salvo La parentela de la Virgen, La Anunciación y el San Cristóbal, que tienen dimensiones mayores ${ }^{47}$. La mayoría de las obras que presentamos, aunque sin fechar (salvo la Anunciación y la santa Justa y Rufina) se pueden englobar en un periodo de madurez del artista en el $2^{\circ}$ tercio del siglo XVIII. Incluso en este grupo observamos diferencias técnicas relevantes entre el cuadro de La Anunciación ${ }^{48}$ y el resto, en especial las Santas Justa y Rufina o la Genealogía de la Virgen donde se manifiesta como un artista de gran calidad técnica y alejado de los estereotipos murillescos.

Para concluir podemos afirmar que las últimas investigaciones sobre Bernardo Lorente y otros pintores coetáneos han arrojado luz a un siglo eclipsado por la figura preeminente del genial Murillo y la primera generación de pintores barrocos sevillanos.

\section{BIBLIOGRAFÍA}

Aranda Bernal, Ana (1989): “Obligaciones de lienzos de Bernardo Germán Lorente para la Cartuja de Jerez”. En: Atrio. Revista de Historia del Arte, vol. 1, Sevilla, pp. 125-126.

Ceán Bermúdez, J. A. (1800): Diccionario histórico de los más ilustres profesores de Bellas Artes en España. Tomo II. VA. Reed 1965.

Cherry, Peter (2013): “¿Retratos a lo divino? Reflexiones sobre las santas de Zurbarán”. En: Navarrete Prieto, Benito: Santas de Zurbarán: devoción y persuasión. [Catálogo de la exposición]. Sevilla: Instituto de la Cultura y las Artes de Sevilla, pp. 37-52.

Clavijo García, Agustín (1979): "Un pintor olvidado: el sevillano Cristóbal López (1671-1730) y so obras en el museo diocesano de Arte Sacro de Málaga”. En: Baetica. Estudios de Arte, Geografia e Historia, Núm. 2, pp. 25-46. Universidad de Málaga.

Galera Andreu, Pedro A. (1988): "Pintura sevillana en Jaén: Lorente Germán y Ruiz Soriano”. En: Archivo Hispalense, Revista histórica, literaria y artística, Sevilla, pp. 207-211.

Gutiérrez Pastor, Ismael (1999): "Dos series de retratos de Bernardo Germán Lorente con un nexo familiar: los Urtusaustegui y los Marqueses de Torrenueva”. En: Archivo Español de Arte, 286, pp. 174-181.

Mata Torres, Josefa (1986): "Nuevos datos sobre Bernardo Lorente Germán”. En Archivo Hispalense: Revista histórica, literaria y artística. Tomo 69, 212, pp. 215-22.

Navarrete Prieto, Benito (2013): “Santas de Zurbarán: devoción y persuasión”. En: Navarrete Prieto: Santas de Zurbarán: devoción y persuasión. [Catálogo de la exposición]. Sevilla: Instituto de la Cultura y las Artes de Sevilla, pp.17-34.

Nieto Cumplido, Manuel (2007): La catedral de Córdoba. Córdoba: edit. Cajasur.

Quiles García, Fernando (1995): "En torno a las posibles fuentes utilizadas por Bernardo Germán Lorente en su pintura: Análisis de la Biblioteca y la pinacoteca de su propiedad”. En: Atrio.Revista de Historia del Arte, 7, pp. 31-43.

Quiles García, Fernando / Cano Rivero, Ignacio (2006): Bernardo Lorente Germán y la pintura sevillana de su tiempo (1680-1759). Madrid: Fernando Villaverde Ediciones.

Romero Asenjo, Rafael / Illan Gutiérrez, Adelina (2006): “La técnica pictórica de Bernardo Lorente Germán”. En: Quiles García, Fernando / Cano Rivero, Ignacio: Bernardo Lorente Germán y la pintura sevillana de su tiempo (1680-1759). Madrid: Fernando Villaverde Ediciones.

Ruiz Barrera, María Teresa (1999): "Una obra inédita de Bernardo Germán Lorente". En: Laboratorio de Arte: Revista del D. de Hist ${ }^{a}$ del Arte, 12, Sevilla, pp. 227-234.

Valdivieso, Enrique (2003): Pintura barroca sevillana. Sevilla: Ediciones Guadalquivir.

Fecha de recepción: 05-IX-2014

Fecha de aceptación: 11-II-2015

\footnotetext{
${ }^{47}$ Mide 2'2 x 1'5 m.

${ }^{48}$ De 1740.
}

Arch. esp. arte, LXXXIX, 354, ABRIL-JUNIO 2016, 183-193

ISSN: 0004-0428, eISSN: 1988-8511, doi: 10.3989/aearte.2016.12 